scarcely be said that it was simply a clever piece of illusion. The Eastern magician presents a similar trick, and much has been made of it in a recent issue of the Illustrated London News. Many Europeans have seen this clever performance, but some at least of those who have described it have not been very skilled observers. What actually occurs is substantially as follows: The girl lies on the ground and is covered up; a sort of tent is built round her; then under cover of it she is raised up ; the tent is gradually taken away bit by bit, until she is seen lying suspended as it were above the ground, but with some of her coverings dropping down to the ground near her head end in what appears a very innocent way. The spectator is not allowed to go up and examine this drapery or he would find out that it conceals an iron post driven into the ground. Were he allowed further license, he would soon discover the secret of the trick, which indeed is very similar to the device used by Maskelyne long ago. An Indian civilian who occupied a high position in the country recently wrote to me describing how he had this trick performed in his compound at a garden-party. Among his guests was a wellknown bishop who was greatly troubled by what he took for a satanic manifestation, until the Commissioner asked him how the man described his performance. "As a trick," replied the bishop. "Well, if he only claimed for it that it was a trick you may be sure it was nothing more. He would certainly not err on the side of modesty in his claims."
In reading of, or in listening to descriptions of this trick as given by men who have not had a training in conjuring-the art of suggestion and misdirection-I would urge readers to be very sceptical. They are often misled to think that events happened far differently from what they actually did. Time after time I have heard people describe what they thought they saw, and knowing how the trick was done I have been astonished that they can have been so hopelessly misled as to the real facts. The success of any and every conjuring show depends on this factor of deception.

We read and hear wonderful descriptions of yogis buried alive and being none the worse for it. In those cases in which expert conjurers have witnessed such experiments, it has been quite clear that the actual conditions were not those claimed by the performer. By means well known to expert magicians-I use the term without prejudice-the suffocation of the subject was easily avoided, though doubtless the experience was sufficiently unpleasant. I know the wonderful claims that have been put forward, but I have so often had the opportunity of checking such claims by careful observation and discovering their worthlessness that I am very far from being convinced.

Once again I would urge readers to look always for a natural explanation of any phenomenon, and when one is not forthcoming, to await the advent of more knowledge, confident that a normal and not a supernormal explanation is always forthcoming, provided that we have the requisite knowledge.

\title{
American Early Tertiary Mammals
}

\section{$\mathrm{T}$} HE White River formation of western North America contains numerous well-preserved fossil skeletons of mammals which date back to Oligocene times when some present-day families were beginning to flourish. The rocks seem to have been formed by floods on a very extensive plain, where the carcases of animals which lived under varied conditions were washed together repeatedly during a long period. The fossils therefore give a very good idea of the mammals which were living on the North American continent during a particularly interesting episode in the evolution of mammalian life. They have already been described in numerous scattered works and papers, but modern methods of collecting have provided so many more satisfactory specimens that there is now an opportunity for a comprehensive review of the whole fauna.
Such a review is being undertaken by Prof. W. B. Scott and Prof. G. L. Jepsen, of Princeton University, who have just published the first part of their work dealing with the Insectivora and Carnivora*. None of the Insectivora has the vacuities in the bony palate and the incompleteness of the zygomatic arches which characterize some existing Insectivora, so that these must be regarded as degenerate, not primitive features. Of the Creodonta or earliest Carnivora, only some Hyænodontidæ survive in the American Oligocene, but very fine skeletons have been obtained from the White River formation. The authors are as much puzzled as previous investigators to explain the use of the long passage above the palate of

\footnotetext{
* The Mammalian Fauna of the White River Oligocene. Part I. Insectivora and Carnivora. Trans. Amer. Phil. Soc., N.S., 28, Part 1. Pp. ii $+153+22$ pl. (Philadelphia : American Philosophical Society ; London: Oxford University Press, 1936.)
} 
Hycenodon by which the internal nostrils are displaced as far backwards as those of a crocodile. They remark that "there is no other feature in the teeth or skeleton of the hyænodonts to suggest amphibious habits". They also point out that Hyoenodon cannot have fed on ants like the existing ant bear (Myrmecophaga), which exhibits a nearly similar arrangement of the palate.

The beautifully preserved skeletons of Canidæ or dogs are especially interesting, because they show that in Oligocene times the family was not so completely distinguished from other Carnivora as it is at present, while one genus, Daphoenus, seems to be the common ancestor of at least three distinct groups of modern Canidæ. The smaller Oligocene dogs must have looked much like civets.

There are very few Mustelidæ in the White River formation. This family seems to have been much more characteristic of the Old World than of the New World during Oligocene times. Of the
Felidæ, no true cats have been found in North America bofore the Pliocene, but the sabre-tooth cats or Machairodontinæ are well represented in the White River formation. They are all much smaller than the familiar 'sabre-toothed tiger' of later date, but it is interesting to observe that the articulation of the lower jaw in the Oligosene genera is as completely adapted for the wide opening of the mouth as it is in the latest Pleistocene genera. There is no doubt that the sabreshaped canines were used for stabbing; and one skull of Nimravus in the museum of the Dakota State School of Mines exhibits a large gash in the brain-case that was evidently made by such a stab.

From this brief summary it is clear that Prof. Scott and Prof. Jepsen are doing much more than providing technical descriptions of the fossils. They are publishing an illuminating treatise on Oligocene mammals, of which the succeeding parts will be eagerly awaited.

\section{Daniel Gabriel Fahrenheit (I686-I736)}

$\mathrm{A}$ MONG the many improvers of the thermometer in the eighteenth century, none laboured more assiduously or successfully than Daniel Gabriel Fahrenheit, the German natural philosopher and instrument maker who died in Holland at the early age of fifty years on September 16, 1736. His work was done at a time when the physical and medical sciences were making rapid advances, and there was great need for thermometers of good construction and furnished with a standard scale which could be used for comparisons. It was this need that Fahrenheit met. He was not the first to make thermometers, the first to use alcohol or mercury, or to devise scales with fixed points, but his improvements were such as to make his thermometers known all the world over, and though to-day it is generally recognized that the universal use of the centigrade scale would be a great advantage, the Fahrenheit thermometer seems likely to remain in use for many years yet.

For nearly a century before Fahrenheit's time, men of science had been using thermoscopes and thermometers, and a grand array of names is associated with their early history. Galileo, Boyle, Huygens, Hooke, Halley and others all contributed to the progress of thermometry. Doctors were especially interested in thermometers by which the temperature of human beings and animals could be taken, while natural philosophers required thermometers as much as barometers. The term 'thermometer' is first mentioned by the French
Jesuit, Father Leurechon (1591-1670), in his "Récréation mathematique" published in 1624. The early instruments were subject to changes in atmospheric pressure and were really 'barothermoscopes'. Ferdinand II, Grand Duke of Tuscany (1610-70), founder of the Accademia del Cimento at Florence, was the first to produce a thermometer unaffected by atmospheric pressure.

There were all sorts of ideas regarding the graduation of thermometers. In 1665 Boyle suggested the freezing point of aniseed oil, and Huygens in the same year suggested as fixed points the freezing point and boiling point of water. Snow in very cold weather, the greatest heat in summer and melting butter were also proposed for definite temperatures. There were also many suggestions regarding scales, about a score of scales being used in the eighteenth century, of which, however, those due to Fahrenheit, Réaumur and Celsuis, or perhaps more correctly Martin Strömer, alone survived.

It is well known that Fahrenheit was the first to bring the mercurial thermometer into general use, that he devised his well-known scale about 1714, and that he described his method of making thermometers in five short papers in Latin to the Royal Society in 1724, but it is not generally known how he came to be an instrument maker. The bicentenary of his death, however, has led to the publication of a biographical memoir in the Transactions of the Royal Academy of Sciences of 